\title{
Erratum to: Arguments from authority and expert opinion in computational argumentation systems
}

\author{
Douglas Walton ${ }^{1} \cdot$ Marcin Koszowy $^{2}$
}

Published online: 6 September 2016

(C) Springer-Verlag London 2016

\section{Erratum to: AI \& Soc DOI 10.1007/s00146-016-0666-3}

In this erratum Fig. 4 has been corrected and the text accompanying Fig. 4 has been altered to fit the requirements of the corrected figure.

\section{Mixing the two kinds of argument}

It is interesting to note that some of the classic cases of argument from authority combine argument from expert opinion with argument from administrative authority. It is also interesting to see how CAS can model cases of evidential reasoning in law where the argument from expert opinion type of authority can conflict with the argument from administrative authority. In Fig. 4, an argument from expert opinion is used as evidence to support the proposition that Smith is guilty of murder, the ultimate claim to be proved by the prosecution (Fig. 4).

The online version of the original article can be found under doi:10.1007/s00146-016-0666-3.

Douglas Walton

waltoncrrar@gmail.com

Marcin Koszowy

koszowy@uwb.edu.pl

1 Centre for Research in Reasoning, Argumentation and Rhetoric, University of Windsor, Windsor, Canada

2 Department of Logic, Informatics and Philosophy of Science, University of Białystok, Białystok, Poland
Let's assume that this argument fits the requirements for the scheme for argument from expert opinion as indicated by the notation $+\mathrm{ex}$ in the argument diagram. Here we have simplified the argument for purposes of illustration by omitting the implicit premises that the matching of the DNA samples shows that Smith was at the crime scene and that this evidence, taken along with the other elements of the crime of murder in a given jurisdiction, provides an argument that supports the claim that Smith is guilty of murder.

But let's look at the counter-argument at the bottom of the diagram. Let's say that this argument is a legitimate instance of the scheme for the administrative argument from authority, as indicated by the notation $+\mathrm{ad}$ in the argument node. The minus sign in the er node indicates that this whole line of argument is a counter-argument attacking the prior argument from expert opinion. In fact, it is shown as an undercutter of that argument, as indicated by the argument from administrative authority being directed to the argument node a1. In CAS, an undercutting argument represents the kind of critical question classified as an exception. In this instance, what it means is that an expert opinion argument based on DNA evidence is generally accepted as a persuasive form of argument in the courts, but a defeasible one that can be refuted if an exception to the general rule is found. In this instance, once the law is stated, along with a citation indicating its source, the undercutting argument - er (exception to a rule) defeats the 
Fig. 4 Expert opinion argument undercut by an administrative authority argument

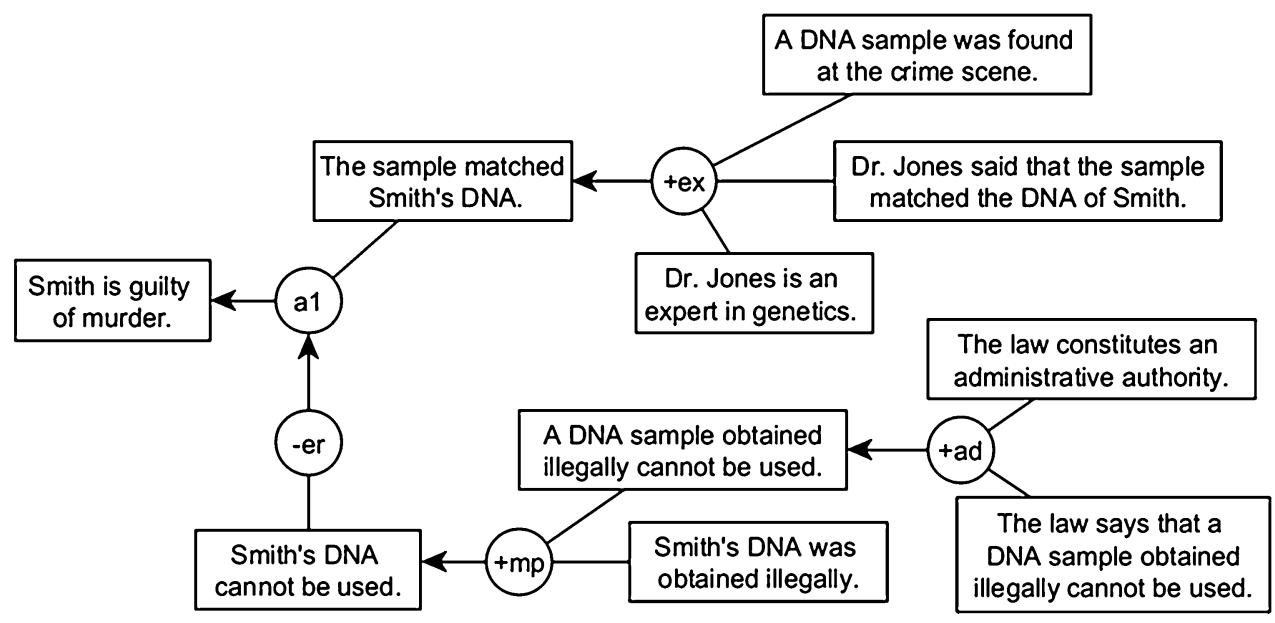

prior argument from expert opinion. The notation $+\mathrm{mp}$ indicates a defeasible modus ponens type of argument (Walton 2016, 227) that has this specific form: $(\forall x)(F x \rightarrow$ $\sim F y$ ); $F a$; therefore $\sim F b$. The $\rightarrow$ symbol represents a defeasible conditional of a kind that is open to exceptions.

\section{Reference}

Walton D (2016) Argument evaluation and evidence. Cambridge University Press, Cambridge 